\title{
TEM STUDY OF THE MICROSTRUCTURE OF Si THIN FILMS DEPOSITED BY HOT WIRE CVD
}

\author{
K.M. Jones, M.M. Al-Jassim, D.H. Levi, and B.P. Nelson \\ National Renewable Energy Laboratory, Golden, Colorado 80401.
}

Si thin films have attracted increasing interest in recent years owing to their applications in thin-film transistors and thin-film solar cells. Such films can be fabricated by different techniques, under very different conditions and can be made amorphous as well as hydrogenated microcrystalline (a-Si and $\mu \mathrm{c}-\mathrm{Si}$ ). Of particular interest is the mechanisms occurring during film growth that are responsible for the transition from amorphous to microcrystalline growth. Improved understanding of these mechanisms may afford a better control of the deposition process and yield a higher performance devices. Furthermore, little has been reported on the structural and morphological properties of such films ${ }^{1,2,3}$.

In this work, we study the properties of a-Si and $\mu \mathrm{c}-\mathrm{Si}$ films grown by hot-wire chemical vapor deposition ${ }^{4}$ under different conditions, such as substrate temperature and the ratio between $\mathrm{H}_{2}$ and $\mathrm{SiH}_{4}$. We also investigate the influence of film thickness and the type of substrate used. The microstructure of the films was studied by plan-view and cross-sectional TEM, while the film morphology was examined by SEM and AFM. Cross-sectional TEM analysis allowed the study of variations in film property along the growth direction. Figure 1 is a TEM cross section of a film (T1999) deposited with no hydrogen dilution. Clearly the film is totally amorphous. Selected area transmission electron diffraction (SAD) exhibited rings corresponding to the Si lattice. Figure 2 is a TEM cross section (T2010) of a film deposited at a higher temperature with hydrogen dilution. The dilution ratio $\mathrm{R}$ (where $\mathrm{R}=\mathrm{H}_{2} / \mathrm{SiH}_{4}$ ) is 4 . This film exhibited a mixture of amorphous and microcrystalline phase. However, the microcrystalline phase seems to be a small fraction of the total volume of the film. SAD examination of this film showed a mixture of rings and spots. Figure 3 is a TEM cross section (T2024) of a film deposited at a higher temperature with a hydrogen dilution ratio $\mathrm{R}$ of 10 . Clearly, this film is microcrystalline throughout. This was corroborated by SAD examination.

This work clearly illustrates the relationship between the film thickness and hydrogen dilution on the one hand, and the film crystallinity on the other hand, as illustrated in the schematic of Fig. 4. At higher dilution levels $(\mathrm{R}>10)$ the films appear microcrystalline from the onset of film growth. At low dilution levels $(R<3)$ the films are amorphous throughout. In the intermediate range $(3<R<10)$ the films consist of mixed amorphous and microcrystalline phases.

\section{References}

[1] J. P. Kleider, C. Longeaud, R. Bruggemann and F. Houze, Thin Solid Films, 383 (2001) 57.

[2] J. Puigdollers, J. Cifre, M.C. Polo, J.M. Asensi, J. Bertomeu, J. Andreu, and A. Lloret, Applied Surface Science, 86 (1995) 600.

[3] M. Stöger, A. Breymesser, V. Schlosser, M. Ramadori, V. Plunger, D. Peiró, C. Voz, J.

Bertomeu, M. Nelhiebel, P. Schattschneider and J. Andreu, Physica B 273-274 (1999) 540.

[4] B.P Nelson, R.S. Crandal, E. Iwaniczko, A.H. Mahan, Q. Wang, Y. Xu, and W. Gao, Mat. Res. Soc. Symp. Proc., Vol.557, MRS, Warrendale, PA, April 1999. 

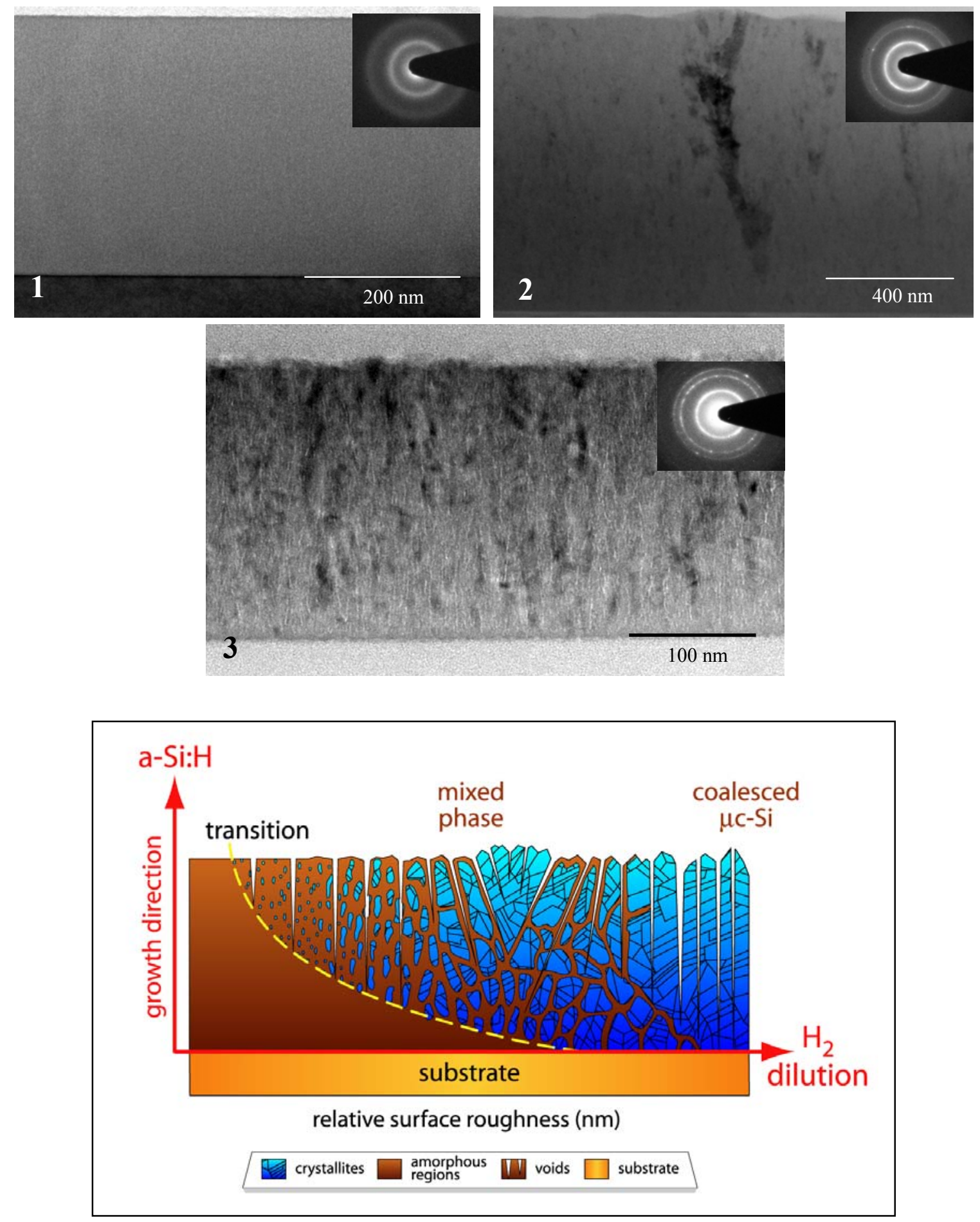

Figure 1. TEM cross-section of a HWCVD Si thin-film deposited with no hydrogen dilution. Figure 2. TEM cross-section of a HWCVD Si thin-film deposited at a higher temperature and with a hydrogen dilution ratio of 4.

Figure 3. TEM cross-section of a HWCVD Si thin-film deposited at a higher temperature and with a dilution ratio of 10 .

Figure 4. Schematic illustration of the relationship between film thickness, hydrogen dilution and film crystallinity. 